\title{
Casas bucarestinas y su función narrativa en La Noche de San Juan de Mircea Eliade
}

\author{
Monica SAVA \\ Departamento de Lengua Española \\ Universidad Spiru Haret de Bucarest \\ monicasava@hotmail.com
}

Recibido: $17 / 02 / 2013$

Modificado: 06/09/2013

Aceptado: 19/09/2013

\section{Resumen}

El mundo narrativo de La Noche de San Juan evidencia el modo particular de estructurar el espacio que Mircea Eliade emplea al nivel textual, consciente de la fragilidad de las fronteras entre el arte y la realidad, la historia y la ficción, lo biográfico y lo imaginario, sin limitarse a crear un mero cuadro de época. A pesar de su evidente carácter de documento, el ambiente bucarestino de la novela resulta ser uno en el cual los eventos históricos representan otras tantas "pruebas del laberinto". El Bucarest de entreguerras se convierte en un espacio mitologizado, un mundo codificado donde lo sagrado puede manifestarse bajo las más banales apariencias, en un universo paralelo donde puede buscarse una posible salida de la Historia.

Palabras clave: espacio urbano, Bucarest, casa, Mircea Eliade.

Title: Houses in Bucharest and their narrative function in Forbidden Forest by Mircea Eliade

\section{Abstract}

The narrative world of the Forbidden Forest points out that Mircea Eliade, aware of the inconsistency of the frontiers between art and reality, history and fiction, biography and imagination, doesn't limit himself to create in his novel a mere frame of epoch. Despite its obvious documentary character, the environment of Bucharest appears as a space where historic events prove to be "trials of labyrinth". The space of inter-war Bucharest acquires mythological values, turns into a codified world where the sacred can manifest itself disguised under the most trivial aspects, into a parallel universe that allows the quest for a possible way out of the History.

Keywords: urban space, Bucharest, house, Mircea Eliade.

\section{Índice}

1. Introducción

2. La casa en invierno

3. La casa en la tormenta

4. La casa museo

5. La casa bombardeada

6. La casa de barrio

7. La casa desierta

8. Conclusiones 


\section{Introducción}

El espacio de la gran ciudad se ha convertido en uno de los grandes tópicos de la literatura contemporánea. En el origen de este fenómeno se halla el aspecto de escenario que toda gran ciudad cargada de historia tiene, cualidad que determina el proceso por el cual esta se transforma en un espacio mental, un escenario para el desarrollo de ideas.

A lo largo del siglo $\mathrm{XX}$, siglo que conoció algunas de las obras fundamentales de la problemática urbana, la novela de la ciudad se convierte en un género en el cual la ciudad no se limita a ser un mero decorado para la acción sino que, a veces, adopta el papel de personaje principal.

Amplio espacio de la realidad inmediata, el espacio urbano llega a ser asequible a la interiorización por la necesidad de redimensionar el existir humano como una extensión de la memoria. Tengan o no referentes reales, los espacios que presenta la ficción son siempre imaginados. Estos mundos ficcionales se insertan en el mundo real por el distanciamiento entre las relaciones espaciales del relato y el lugar del lector. En la organización de la estructura del espacio novelesco intervienen necesariamente objetos, detalles, las luces seguidoras y también la presencia de un observador con su propia perspectiva.

La ciudad como realidad multifacética es mucho más que su espacio geográfico. Localización de la relaciones entre sus habitantes, el ambiente urbano es texto y contexto en un perpetuo proceso de reconfiguración, en el cual las estructuras urbanas se convierten en construcciones simbólicas e imaginarias. Como observa Gaston Bachelard, el tema espacial presenta un alto grado de ambigüedad como consecuencia de la falta de identidad entre el espacio que aparece en el texto literario y el espacio físico (Bachelard 1994: 18).

En el caso de la prosa de Eliade, se pueden comprobar tanto su capacidad de dar vida a un mundo concreto de objetos, como su deseo de mantener la confusión para sumergir al lector en el misterio y en el sueño, al igual que su aparente intención de persuadirlo de que la localización geográfica de su narración es importante. De este modo, el entorno presentado cobra, igual que el de una fábula, validez universal.

En La Noche de San Juan, a nivel textual, tanto los elementos espaciales como los temporales actúan como signos o pueden tomar, igualmente, valor simbólico. El simbolismo de los lugares incluidos en el espacio de una novela permite vincularlos con lugares recurrentes afines a sus referentes reales 0 , por lo contrario, con motivos espaciales cargados de significado psicológico o con valor mítico.

La ciudad contemporánea sigue conservando imágenes y símbolos y es, a la vez, como escribe Eliade, siempre una 'imago mundi', una "nueva imitación, una repetición de la Creación del 
Mundo", visto que a todo lo que hay en el mundo humano le corresponde un modelo celeste (Eliade 2008: 17).

En el Bucarest eliadiano las metáforas espaciales llegan a funcionar como instrumento de búsqueda del vivir simultáneo dentro y fuera del mundo, y el espacio urbano se presenta como una "geografía mítica"1. A pesar de esto, el espacio bucarestino descrito abunda en topónimos reales, los cuales, por reflejo metonímico, amplifican la sensación de autenticidad de lo narrado, produciendo un "efecto de lo real" (Barthes 1982: 81-90).

Así que en este espacio construido por el lenguaje novelesco de La Noche de San Juan, la imagen concreta de la ciudad -Bucarest al estallar la Segunda Guerra Mundial- toma prestados elementos del mundo real y presenta un alto grado de mimetismo. Se puede observar que las coordenadas topográficas que enmarcan el espacio interior en el cual se mueven los personajes se limitan generalmente a un área bastante restringida en la configuración del Bucarest de entreguerras, que corresponde más o menos al centro de la capital rumana. Las habitaciones en que viven los héroes de la novela eliadiana son, en su mayoría, casas bucarestinas con jardines y, raras veces, pisos en edificios más altos (figura 1 ).

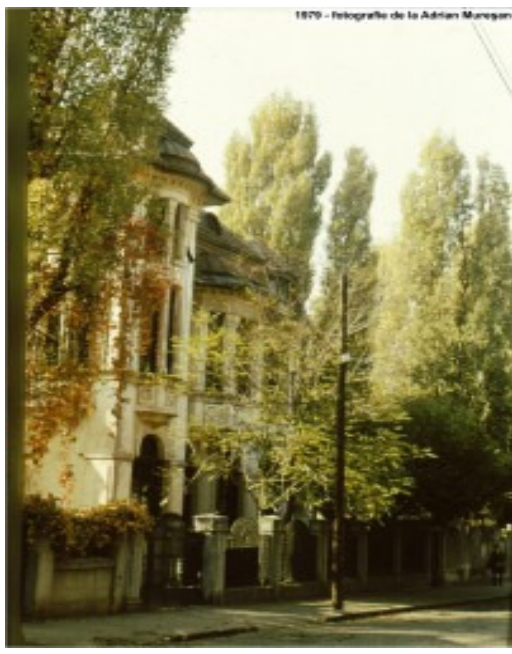

Figura 1. Casas céntricas bucarestinas con arquitectura característica del

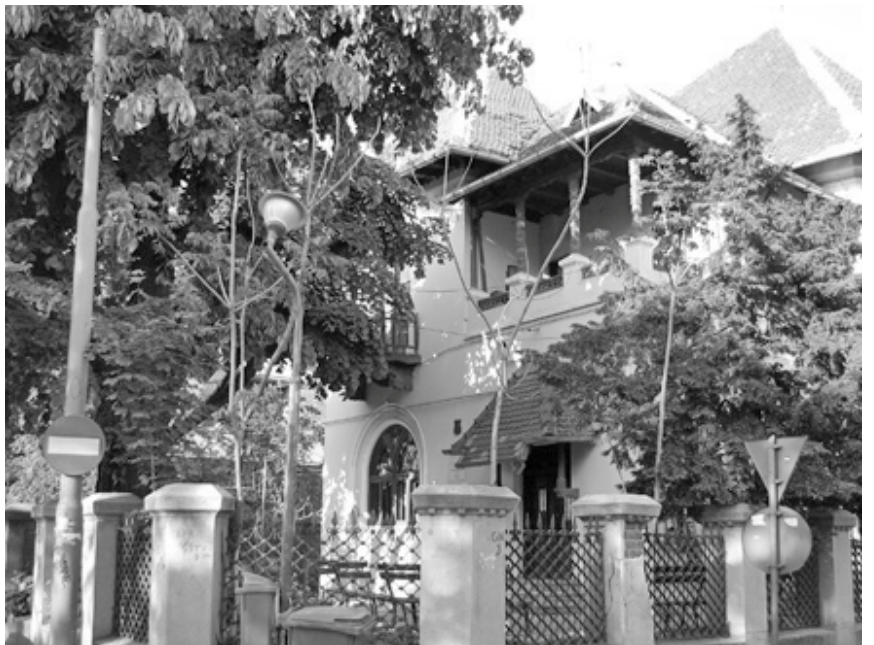

Fuente: bucurestivechisinoi.blogspot.ro período de entreguerras.

Sus descripciones recomponen gradualmente una extensa imagen de la vida cuotidiana del Bucarest de entreguerras y atestiguan las características constructivas que diferenciaban la

1 "La tierra natal constituye una geografía sagrada y, para los que la han abandonado, la ciudad de su infancia y adolescencia llega a ser una ciudad mítica. Para mí, Bucarest es el centro de una mitología inagotable. Gracias a esa mitología pude conocer su historia" (Eliade 2008: 33-34). 
capital rumana de las "ciudades tentaculares" cuyos habitantes vivían en "cajas superpuestas".

Esta concepción arquitectónica confiere a las relaciones que se establecen entre el mundo y estos espacios de máxima protección que son las moradas, un valor distinto del convencional, una dimensión cósmica. Asediados por las fuerzas cósmicas, se resisten, amplificando su valor protector.

Todas estas imágenes espaciales destacan en igual medida por su especial representatividad para la vida de los personajes y la historia de la capital rumana, pero algunas conllevan un simbolismo más profundo.

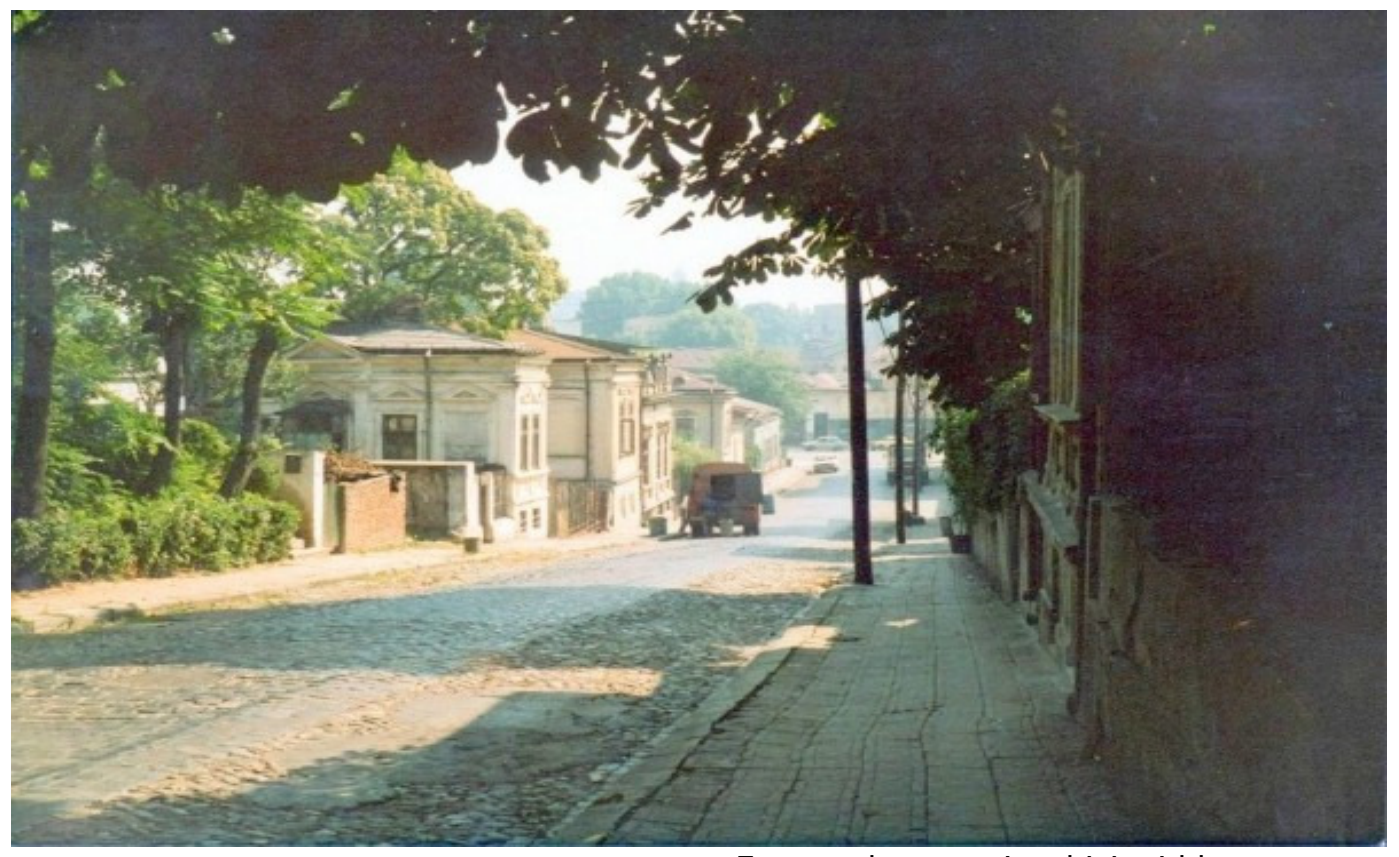

Fuente: bucurestivechisinoi.blogspot.ro

Figura 2. Calle típica de la primera mitad del siglo XX en Bucarest.

\section{La casa en invierno}

La casa en invierno está representada por la habitación de Catalina, actriz del Teatro Nacional cuyos sentimientos oscilan entre el actor Dan Bibicescu y el profesor de filosofía Petre Biris. A pesar de ser tan sólo un apartamento, posee todos los valores de intimidad y de protección, de la morada en invierno, valores que se siguen incrementando en el más alto grado ante las fuerzas desencadenadas de la tormenta de nieve.

En toda la secuencia del cuarto de Catalina está presente la misma técnica contrapuntística que utiliza Eliade, contrastando la descripción de la nevada con el diálogo entre los dos héroes sobre la guerra y sus consecuencias. En esa ciudad sepultada bajo la nieve, Biris y Catalina parecen dos sobrevivientes que luchan desesperadamente para oponerse a la invasión del frío y del viento en 
su espacio interior, para impedir el acceso de esas manifestaciones ciegas y violentas, portadoras de un mensaje de desequilibrio, de ruptura cósmica. Su empeño se manifiesta, en el plano espacial, en su intento de tapar las rendijas de la ventana con trozos de periódico, mientras que en plano existencial, se refleja en su relación amorosa, como un gesto dedicado a mantener el fuego de la vida.

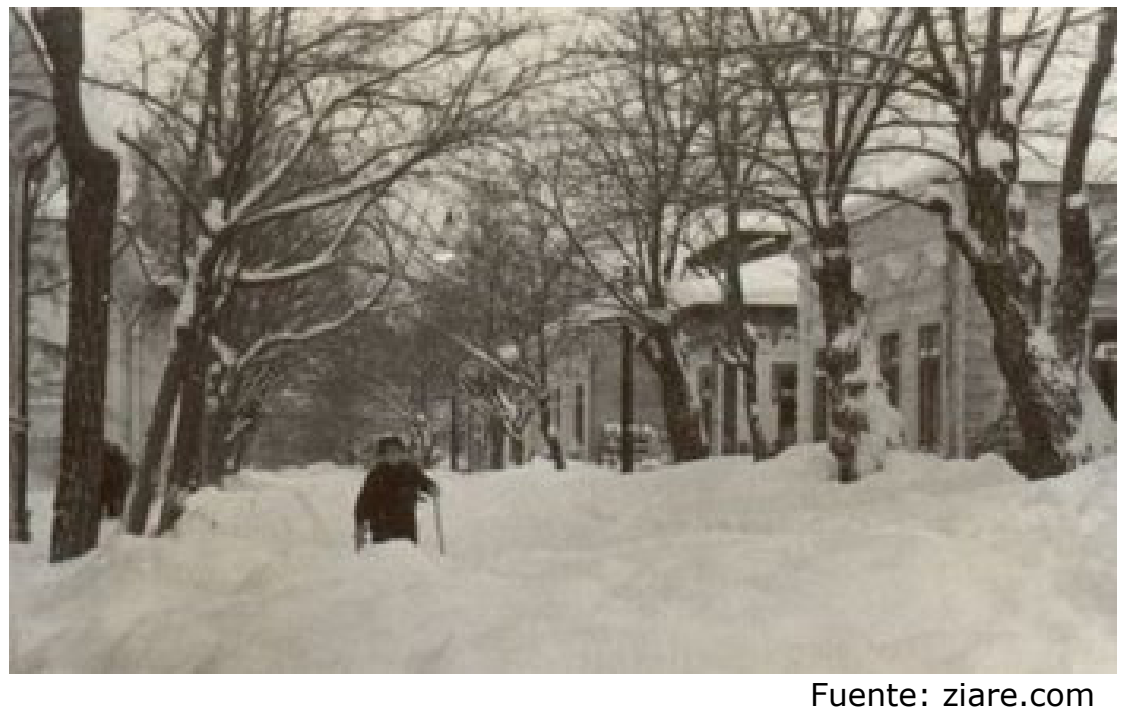

Figura 3. Invierno en Bucarest.

La nieve aniquila el mundo exterior, sumerge toda la ciudad. Bajo su blancura los caminos se desvanecen, así como el destino de los dos personajes va a confundir los caminos de sus vidas, que serán borrados en la confrontación con las fuerzas exteriores. Viento y nieve se arrojan sobre este espacio protector. El mundo exterior asedia ese espacio habitado y el invierno que ruge como un dragón sugiere todos los peligros que están al acecho: el frío, la destrucción, la guerra.

\section{La casa en la tormenta}

Para describir la casa en la tormenta, Eliade se sirve de una técnica contrapuntística. La casa de Ileana, aunque esté situada en la ciudad, al contrario de la tesis de Bachelard sobre la falta de cosmicidad de las viviendas urbanas, se enfrenta violentamente con la tempestad. La descripción sorprende minuciosamente la ofensiva del viento, el azote de la lluvia, el estrépito de los truenos que vienen presentados en un crescendo musical, en un movimiento sinfónico. En una vasta orquestación en la que abundan las alusiones sonoras, se intercalan fragmentos de las acciones y de los diálogos entre los tres personajes presentes: Ileana, Stefan y su amigo Biris. En un tercer plano se añaden los pensamientos y los recuerdos de dos de ellos, Biris e Ileana. Frente al ataque de las fuerzas cósmicas, la casa de Ileana cobra valor humano aludiendo a la capacidad de resistir frente a la 
hostilidad exterior y también ante la fragilidad y la angustia interiores.

Al caso particular de la casa de Ileana se le puede aplicar perfectamente la imagen metafórica, en términos de la poética de Bachelard, de "la casa como un corazón angustiado". La escena que ocurre en la casa de Ileana se abre con la mención, en una sola oración, de las señales presagiosas, que siguen amplificándose cada vez más, y será atravesada por el diálogo entre los eventos exteriores y lo que pasa dentro. El cielo "plomizo e inmóvil" empieza a ser amenazador cuando Biris le transmite a Ileana el mensaje de Stefan. Desde fuera empiezan a oírse truenos lejanos y las hojas del árbol frente a la ventana comienzan a temblar cuando los dos hablan de la muerte de Partenie y de la conmoción nerviosa de Stefan. Los movimientos de las ramas del árbol se intensifican a medida que la tensión y los sentimientos dentro de la casa crecen, hasta sugerir la mano del destino llamando a la ventana: "La rama había empezado a cobrar vida y temblaba con un extraño silbido, golpeando cada vez con más fuerza el cristal" (Eliade 1998: 228).

La afirmación de Ileana -"empieza la tormenta..."- suena como un presagio que ella misma aún ignora, acerca de la confrontación de los personajes con su destino. El quejido de la tormenta parece reduplicar el lamento de Ileana de no entender a Stefan, mientras la iluminación sugerida por los relámpagos viene a enfatizar la aceptación de lo que siente por él. Toda esa tormenta exterior aparece como la manifestación explícita de los sentimientos que Ileana inconscientemente se niega reconocer, de las señales celestes a las cuales se opone tan valientemente como lo hace su casa:

Ahora llovía a cántaros, casi con furia, y la rama se debatía aterrorizada, golpeándose desesperadamente contra el cristal. Los relámpagos arreciaban. Había momentos en que la casa entera parecía sacudida desde los cimientos. (Eliade 1998: 229)

En el caso del otro personaje presente en la casa de Ileana, el profesor Biris, asistimos a su lucha contra de la enfermedad que lo consume mientras que, como relámpagos, se desencadenan en su memoria recuerdos de su infancia que le revelan las causas del inicio de esa enfermedad suya.

A lo largo de toda la escena, la tormenta viene relatada en su desarrollo desde las primeras señales hasta su auge; desde los ruidos lejanos de los truenos y las primeras gotas de lluvia, hasta los fuertes relámpagos y los tronidos que sacuden los cristales, las ráfagas de viento y lluvia que hacen temblar la casa. Es evidente en toda la descripción la abundancia de detalles sonoros. La tempestad se oye primero en la lejanía, luego, su voz se refuerza hasta tronidos y 
vendavales, golpes de las ramas retorcidos contra los cristales y ráfagas de lluvia.

Esa casa que desafía "las iras del cielo", que ofrece refugio y protección, que parece darles consejos de resistir a los tres personajes, acabará más tarde vencida en la confrontación con las fuerzas destructivas, pereciendo en un bombardeo americano de la Segunda Guerra Mundial sobre la capital rumana. Sin embargo, no la vemos derribada. Al buscarla, años más tarde, Stefan encuentra en su lugar los andamios de una nueva construcción y el hecho parece sugerir que así como ella desaparece para renovarse, los tres héroes aún pereciendo físicamente, no serán destruidos.

\section{La casa museo}

Entre las casas de la novela eliadiana, cuyas imágenes suelen recomponerse con gran escasez de detalles, la casa del profesor Antim, la casa museo, destaca por la riqueza de detalles de índole realista. A pesar de esto, el cuadro que se deja ver es el de una casa enigmática, cuyo misterio se debe, en cierta medida, al contraste entre su aspecto exterior modesto, casi feúcho, y la riqueza interior, menudeando de reliquias del pasado, aglomerando "cosas muertas" que le confieren un aire entre museo y mausoleo, vestigios de "un pasado sin herederos". Pero lo que la distingue particularmente, es su misterioso poder de influir en la suerte de sus habitantes, que podría surgir precisamente de esa belleza interior suya.

Obviamente puede incluirse la casa del profesor Antim en el tipo de "casa vivida"" mencionada por Gastón Bachelard, un espacio que funciona como instrumento de topoanálisis para los personajes que habitan allí (Bachelard 1994: 38). Sin embargo, en este caso, entre la casa y su propietario, el profesor Antim, a pesar de su interés de coleccionista, no existen vínculos afectivos y demasiado fácilmente renuncia a este espacio y a su valioso contenido de objetos antiguos en busca de enriquecerse con la venta de un cuadro. La casa abandonada lo abandonará a su vez. Así, el profesor Antim, privado de toda protección, no será más que un ser vulnerable que encontrará un fin lamentable muriendo en un banco de una estación londinense.

Al ser abandonada por su propietario, la casa se procura otros moradores para los cuales tendrá una significación diferente. Ese espacio que no le pertenece en absoluto, le enseña al maestro de provincia Gheorghe Vasile una lección de generosidad y honestidad, contribuyendo a su desarrollo como ser humano. Vive en esa casa un pasado que, si está muerto para el profesor Antim, se convertirá en tradición para Gheorghe Vasile o en mito para el actor Dan Bibicescu.

Por lo tanto, no sería gratuito afirmar que el espacio de la casa del profesor Antim es un espacio redentor. Si el que la ha 
abandonado es castigado, en cambio, los que han venido a habitarla sufrirán un proceso de regeneración como seres humanos.

Esta función opera tanto en el caso del maestro Gheorghe Vasile, que vende los objetos valiosos, como en el caso del actor Dan Bibicescu, al cual le ofrece generoso asilo cuando es perseguido por la policía política. Además, para este actor adocenado, este espacio privilegiado será mucho más que un refugio. El vivir en este espacio le permitirá al vanidoso Bibicescu llegar a ser lo que siempre ha deseado, un verdadero dramaturgo. La voz del pasado guardado allí le ayuda a Bibicescu a hallar la fuente de su inspiración y dar el espectáculo de su vida, concluido con su muerte dramática. Su fin espectacular y ejemplar al mismo tiempo, en vez de perderle, le confiere un nuevo sentido a su vida.

Es este ambiente uno de aquellos en que "los objetos ascienden a un nivel de realidad más elevado, consiguiendo propagar una nueva realidad de ser, de modo que la casa se reconstruye desde el interior" (Bachelard 1994: 35-38).

La descripción exterior es sumaria y carece de significación, mientras que el interior viene descrito repetidamente a lo largo del libro, siempre acumulando otros detalles descriptivos. Es la imagen de un espacio que conserva elementos de la tradición y la historia nacional rumana. Los objetos allí guardados por el profesor Antim demuestran ser más que meros testimonios del pasado, antiguos manuscritos, libros preciosos, cuadros e iconos, etc.; consiguen sugerir que el pasado nunca está muerto y que sigue viviendo en el ciclo del Tiempo.

De todas las casas de esta novela, la del profesor Antim prueba la opinión de Bachelard de que este tipo de espacio es "más aun que el paisaje, un estado de alma". Es un tipo de espacio capaz de operar una transformación sobre los que viven dentro -también dentro del pasado, de la tradición, de la moral- ayudando a cada uno de sus moradores a construir su propio "castillo interior" (Bachelard 1994: 29).

\section{La casa bombardeada}

Una de las casas que desgraciadamente no resiste a la hostilidad exterior, cediendo a las fuerzas destructivas, es la casa bombardeada, la casa de Ioana y Stefan.

Entre tanto, el salón de la propia casa de Stefan, donde su hijo Razvan está jugando con unas cajas en la alfombra, se convierte en un espacio mítico, visto que lo que ocurre en esta escena doméstica se entreteje a nivel textual con la rememoración de la visita del protagonista a casa de Anisie y, por lo tanto, fragmentos y replicas de las dos historias se suceden sin ruptura alguna como si formaran parte del mismo dibujo, del mismo plano. La visita real y la conversación entre Stefan y Anisie se convierten en leyenda, en un 
cuento de hadas para el niño que está jugando, un cuento en el cual aparecen como personajes su padre Stefan, que es el Emperador; Anisie, el apicultor asceta; el Rey Pescador; los caballeros del Santo Grial; Parsifal e incluso Dios.

Sin duda alguna, la construcción textual remite a la convicción eliadiana conforme a la cual el mito y la leyenda no faltan nunca en nuestra vida cotidiana y nos acompañan siempre, disimulados, camuflados a veces bajo la más trivial apariencia, de tal modo que el paradigma de nuestra realidad constituye una contextura de lo profano y de lo sagrado, que es susceptible de ser desvelada sólo por una continua concentración de la atención que nos pueda proporcionar la capacidad de hacer la pregunta justa.

Perdiendo su condición de espacio protector, la casa llega a ser la "última morada" de Ioana y Razvan, la mujer y el hijo de Stefan. Sus moradores, así como Irina intenta explicarle a Stefan que continúa apartando los escombros, "ya no están allí. Se han ido..." (Eliade 1998: 381). La casa perece junto a los seres que abriga, pero la imagen de sus ruinas sobre las cuales brotan flores azules es una metáfora muy clara acerca de la permanencia de lo espiritual aun después de la destrucción del caparazón material:

No se habían retirado las pilas de escombros, pero ahora parecían más compactas, más bajas, y entre ellas había crecido la hierba y la maleza. Biris se paseaba lentamente, tratando de reconocer el sitio donde había estado la casa. Llegó encontrarla. En el montículo de escombros todavía sobrevivían unas flores azuladas, descoloradas. (Eliade 1998: 441)

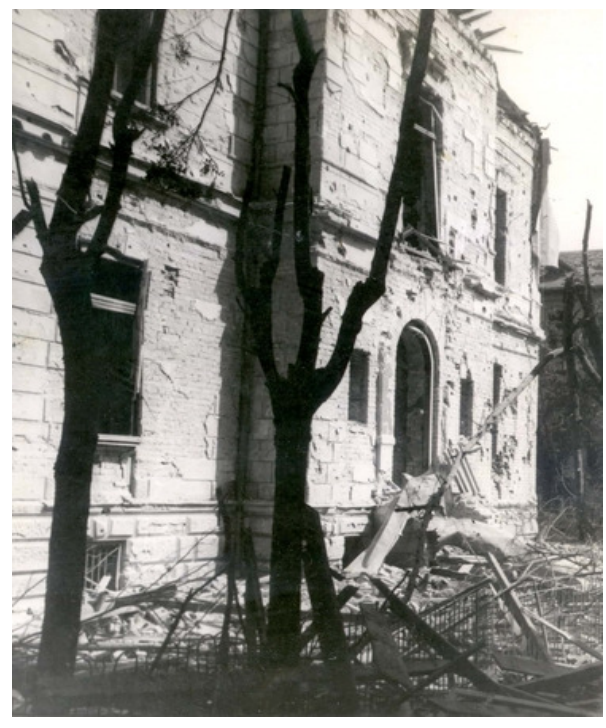

Fuente: turistinbucuresti.blogspot.ro

Figura 4. Ruinas en Bucarest después de los bombardeos americanos en la Segunda Guerra Mundial. 


\section{La casa de barrio}

La casa donde vive Petre Biris, el amigo de Stefan, situada en el plano espacial en un área intermedia entre el centro y las afueras y que se parece a una casa rural, era un tipo muy frecuentemente encontrado en el Bucarest de entreguerras. A pesar de su humilde aspecto esa casa de su tía, ubicada en la calle de Macelari, es la vivienda de un profesor de filosofía. Su imagen se compone menos de elementos descriptivos concernientes a su aspecto exterior o interior, y más de detalles y alusiones a lo que allí ocurre. Esa simple casa de barrio es, sobre todo, un espacio vivido, un espacio de la conversación y de la amistad.

Es el lugar de las largas charlas entre amigos, sobre todo con Stefan, o de la meditación filosófica; pero al mismo tiempo de la vida cotidiana de Biris y de su tía, la señora Porumbache. Un modesto cuarto de una casa bucarestina periférica, cuyas paredes están cubiertas de libros de filosofía y donde la señora Porumbache sigue recordando su pasada opulencia, llega gradualmente a ser el espacio de la pobreza, del sufrimiento, de la enfermedad o de la muerte, pues aquí permanece guardando cama Biris mientras su enfermedad va agravándose, y aquí también se entera de la muerte de su amante, Catalina. Esa morada bucarestina de un profesor de filosofía que pretende "vivir en paz con la Historia" será invadida sucesivamente, como una ironía de la suerte, por la realidad de la guerra, bajo la apariencia de un soldado ruso borracho y, por la muerte, cuando Irina lleva hasta allí la noticia del fallecimiento de su amigo, el actor Dan Bibicescu.

Indudablemente, la escena con el soldado ruso que penetra en el modesto interior de una casa de un suburbio bucarestino es una de las más impresionantes de toda la novela. Una Nochebuena en el Bucarest ocupado por las tropas soviéticas, en la humildísima habitación de un profesor de filosofía afectado de tuberculosis, reducido a la más absoluta pobreza, sufriente en su mísera cama, resulta impresionante y sugestiva la aparición intempestiva de un soldado ruso en busca de bebida, igual que su danza en torno a un garrafón de vino tinto, una danza a la vez macabra y guerrera, a la cual pretende asociar a Irina, venida a anunciar la muerte del actor Bibicescu, amigo de Biris. Bajo esta perspectiva, el soldado ruso parece cumplir una especie de ritual dionisiaco, que ocasiona la ruptura de los límites del orden establecido, determinando por este mismo acto la irrupción de la Historia en este espacio y, por lo tanto, un trastorno en la vida de Biris. Igualmente obvio resulta el significado cosmogónico de esta danza, sugiriendo la inversión de la relación entre el cielo y la tierra que la ideología comunista va a producir en la sociedad rumana.

Es una ocasión más para observar cómo utiliza Eliade la representación de los motivos espaciales en un proceso de 
transformación, con el fin de sugerir que ningún espacio, por protector que parezca, puede resistirse a las fuerzas que dirigen el mundo y que, por cerrado que sea, siempre tiene una salida.

\section{La casa desierta}

En el límite de la ciudad, en aquella zona ambigua entre terreno urbanizado y campo, zona de barracas, chabolas y zanjas, perdida entre jardines, maizales, bancales de pepinos y tomates o flora selvática, aparece la casa desierta.

En una de las más amplias escenas, a lo largo de la cual se desarrolla la fuga de Gheorghe Vasile y de su nuera, Irina, ante la invasión de las tropas soviéticas con el propósito de poner a salvo los libros de divulgación de la colección 'Biblioteca para todos', aparece representada una vasta zona periférica de la capital rumana. Es una zona caracterizada por callejuelas que terminan en senderos sobre los cuales reina el omnipresente polvo. A pesar de la falta de elementos propios de la civilización urbana, el ambiente se salva de la impresión de promiscuidad por la presencia todopoderosa y perenne de la naturaleza que no se deja domesticar. Desde esta perspectiva, la ciudad parece ser un "mundo de fuera" de donde llegan noticias y ecos lejanos de guerra y destrucción. Sin embargo, todo ese territorio incivilizado de calles que desaparecen entre las malas hierbas y el polvo, desde donde la ciudad de Bucarest se ve o, más bien, se oye, como una realidad bastante lejana, nada tiene de ciudad degradada. En ese escenario que adquiere valores de espacio iniciático, busca su camino el maestro Gheorghe Vasile con su carro lleno de libros que quiere salvar de la invasión de los rusos. Este ambiente de casuchas y chozas que, lejos de sugerir la miseria, remiten más bien a la expresión de la forma originaria de habitación, reducida a lo esencial y completamente integrada en el orden natural, se convierte en imagen metafórica de un espacio fuera del Tiempo histórico, en que funcionan otras leyes, las de la Naturaleza.

Es una imagen de comienzos del mundo, la de un territorio perteneciente a las leyendas, a la eternidad. Es un territorio en el cual la ciudad con todo lo que le es propio simplemente se diluye hasta desaparecer, una zona que, careciendo de civilización, no carece de cosmicidad. De este modo, la casucha desierta, perdida en este territorio donde se desarrolla la odisea de los libros, revela su sentido simbólico que asimila la casa a la zona mítica en la cual se hallan las raíces de toda tradición que la civilización moderna está a punto de perder, de destruir. 


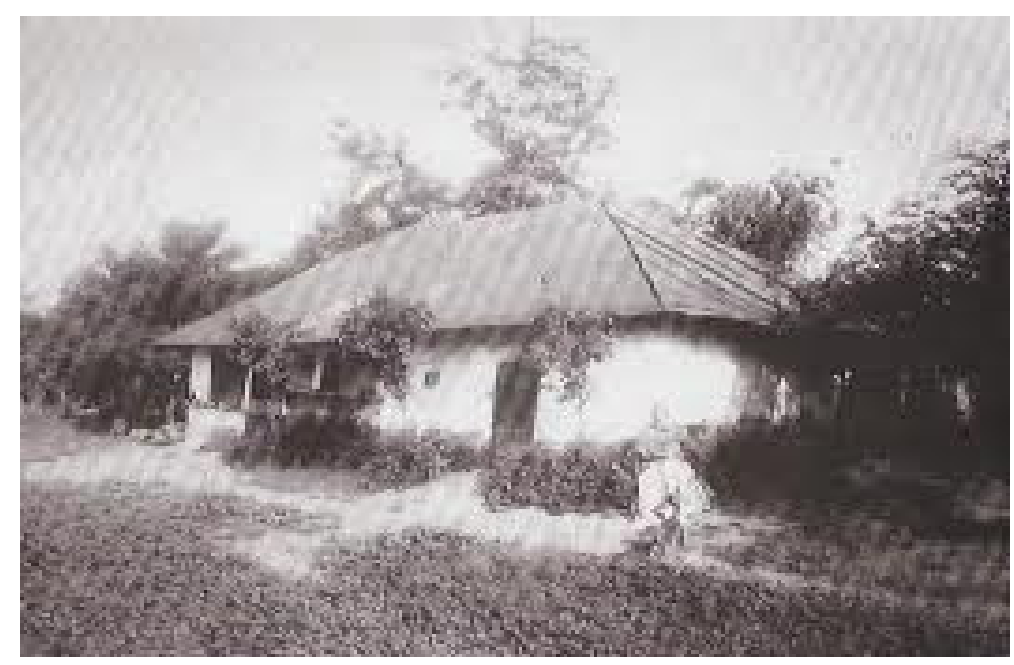

Fuente: google.ro

Figura 5. Casa a las afueras del Bucarest de entreguerras.

Las casas de La Noche de San Juan no sólo "conocen los dramas del Universo" sino que también participan en ellos.

\section{Conclusiones}

En La poética del espacio, Bachelard parte de la premisa de que la psique es un lugar, y que la casa es una extensión de ese lugar y, por consiguiente, tanto la casa como la conciencia almacenan recuerdos. En su opinión, la casa puede ser considerada como un ser privilegiado, la imagen de la intimidad protegida, "nuestro primer Universo", mientras desde un punto de vista metafísico, su situación resume la situación del hombre en el mundo (Bachelard 1994: 18).

Considerando que "el poeta puede amasar el universo en torno a un objeto" y que con su imaginación puede hacer cosas extrañas de elementos familiares, Bachelard afirma que este, convirtiendo el texto en un complejo de sentimientos, nos proporciona la manera de tomar conciencia del nuevo mundo ante el cual nos sitúa por un detalle poético. Basta una simple imagen, si es nueva, para abrir un mundo (Bachelard 1994: 104).

Como la casa tiene un valor mediador entre el hombre y el mundo, Bachelard considera que, para el estudio fenomenológico del espacio interior, la casa es "un ser privilegiado" que, debido a su complejidad, tiene uno de los mayores poderes de integración para los pensamientos, los recuerdos y los sueños del hombre, visto que las imágenes de la casa están en el ser humano tanto como el ser humano está en ellas y que sin ella, como su primer mundo, el hombre sería un ser disperso.

La estética moderna considera que los textos de ficción no se limitan simplemente a "pintar" los mundos, sino que los crean. Según Toma Pavel, la literatura crea mundos de ficción mencionando que los enunciados ficticios se refieren a los mundos posibles creados por el 
autor y reconstituidos por el lector. Debido a esas convenciones de la ficción, los enunciados literarios son percibidos como representaciones de estructuras lingüísticas, representaciones que generan su propio contexto semántico. Al mismo tiempo, las convenciones de la ficción advierten a los lectores de que los mecanismos referenciales habituales están en gran medida suspendidos y que, para el entendimiento de un texto literario, los datos exteriores significan menos que en las situaciones cotidianas (Pavel 1992: 202-203).

La Noche de San Juan se desarrolla en un ambiente conocido, un espacio familiar, y lleva consigo una importante carga autobiográfica, aunque el autor reconoce la fragilidad de las fronteras entre el arte y la realidad, la historia y la ficción. Hay en el texto eliadiano una ambigüedad que resulta amplificada, primero, debido al carácter equívoco del espacio urbano mismo, a la vez abierto y cerrado; y luego, por la función que desempeña. El repertorio de los elementos espaciales propios de la geografía urbana pone de manifiesto la recurrencia del motivo de la casa y, al mismo tiempo, su función narrativa que tiene por objeto la correlación entre los cambios de lugar y la historia.

Las casas descritas por Mircea Eliade en La Noche de San Juan no ofrecen una representación de tipo realista, un dibujo objetivo que constituya, en primer término, un documento que señale una geografía o aluda a una biografía precisa, una representación o una copia de la realidad. En la novela de Eliade el mundo se desarrolla como un laberinto de señales que no corresponde a un mundo cotidiano codificado, sino que más bien consigue configurar otro tipo de espacio, un universo paralelo.

Los personajes de esta novela viven en las casas de un Bucarest mitologizado, convertido en espacio iniciático, lleno de misterios que se ofrecen para ser descifrados, un laberinto de pruebas de todo tipo. Este espacio del Bucarest de entreguerras, ampliamente rememorado en La Noche de San Juan, forma igualmente un topos de inagotable nostalgia para el autor. 


\section{Bibliografía}

ALEXANDRESCU, Sorin (2007): Mircea Eliade, dinspre Portugalia. Bucuresti: Humanitas.

BACHELARD, Gaston (1994): Poética del espacio. México: F.C.E.

BARTHES, Roland (1982): "L'effet du réel", en Littérature et réalité, pp. 8190. Paris: Seuil.

ELIADE, Mircea (1998): La Noche de San Juan. Barcelona: Herder.

- (2008): Mitul eternei reintoarceri. Bucuresti: Univers Enciclopedic.

MARINO, Adrian (1980): Hermeneutica Iui Mircea Eliade. Cluj: Dacia.

PAVEL, Toma (1992): Lumi fictionale. Bucuresti: Minerva.

RUSTI, Doina (1997): Dictionar de simboluri din opera lui Mircea Eliade. Bucuresti: Coresi.

SIMION, Eugen (2005): Mircea Eliade, nodurile și semnele prozei. Bucuresti: Univers Enciclopedic. 